\title{
Nonlinear analysis of thermal behavior for a small satellite in Low Earth Orbit using many-node model
}

\author{
Pham Ngoc Chung, Nguyen Dong Anh and Nguyen Nhu Hieu
}

\begin{abstract}
In this paper, nonlinear thermal responses of a small satellite in Low Earth Orbit (LEO) are analyzed using many-node model. The main elements of primary structure of the satellite include six rectangular cover plates and a solar array linking with satellite's body. These elements can be modeled as different lumped thermal nodes. We use an eight-node model for estimating temperatures at nodal elements i.e. six nodes for cover plates, and two nodes for front and rear surfaces of the solar array. The nodes absorb three major heat energy sources from the space environment consisting of solar irradiation, Earth's albedo and infrared radiation. The established system of thermal balance equations for nodes is nonlinear and is solved by a numerical algorithm. For simulation purpose, it is assumed that the satellite always remains Earth-pointing attitude during motion. Temperature evolutions of nodes in time are explored in details. The obtained results show that the predictive temperature values of nodes are within the allowable temperature limit range of the satellite.
\end{abstract}

Index Terms-small satellite, Earth- pointing, thermal response, temperature limits.

\section{INTRODUCTION}

$\mathrm{T}$ hemal analysis is one of the most important tasks in processes of designing, manufacturing and launching a satellite. It guarantees that all kind

Manuscript Received on July 13 ${ }^{\text {th }}, 2016$. Manuscript Revised December $06^{\text {th }}, 2016$.

This research is funded by Vietnam National Foundation for Science and Technology Development (NAFOSTED) under grant number: "107.04-2015.36".

Pham Ngoc Chung, Faculty of Basic Sciences, University of Mining and Geoology, Duc Thang, Bac Tu Liem Dist., Hanoi, Vietnam (e-mail: chunghumg86@gmail.com).

Nguyen Dong Anh, Institute of Mechanics, Vietnam Academy of Science and Technology, 264 Doi Can Str., Ba Dinh Dist., Hanoi, Vietnam (e-mail: ndanh@imech.vast.vn).

Nguyen Nhu Hieu, Institute of Mechanics, Vietnam Academy of Science and Technology, 264 Doi Can Str., Ba Dinh Dist., Hanoi, Vietnam (e-mail: nhuhieu1412@gmail.com). of equipment of satellite will work within allowable temperature limits $[1,2,3]$. The prediction of temperature fluctuations under the effect of space environment aims to design thermal for satellites in the early stage of space missions. One can use a single-node, two-node or many-node model for estimating temperatures of satellite. For simple thermal models such as single-node or two-node model, analytical methods can be used, for example, the Fourier analysis method [4], techniques of linearization method $[5,6]$. In the work by Grande et al. [7], they utilize a technique for linearizing nonlinear terms relating to the thermal radiation of a two-node model. Their obtained linearized system takes the form that is similar to conventional mechanical system subjected to periodic excitations and easy to solve analytically. By employing perturbation and numerical methods, Gaite et al. [8] showed that the temperature response of the satellite model approaches an attracting limit cycle. In 2012, Gaite et al. [9] studied a simple single-node model for a small satellite orbiting around a solar system planet. More recently, Anh et al. [10] have extended an equivalent linearization technique based on the dual replacement concept for finding approximate thermal responses of a single-node satellite model in the Low Earth Orbit. Some other analytical techniques for analyzing satellite thermal can be found in work by Gaite [11]. In fact, due to the complexity of the geometrical model of satellites, thermal equations of satellites are discretized into many-node in which each node is characterized by a temperature at any time. If using analytical methods, solving such a many-node system is not easy.

The current study is devoted to the use of a numerical method to analyze thermal behavior for a small rectangular parallelepiped satellite in Low Earth Orbit using eight-node model. The obtained result shows temperature evolutions of nodes in 
time and temperature values are within allowable limit. We also examine the effect of the solar absorptivity and the emissivity on the satellite's thermal responses.

It is noticed that modeling of thermal loadings acting on satellite is not available for almost thermal analyses using many-node models. This is because of the complexity of modeling of thermal inputs and of the dependence on orbital configuration, motion characteristics and mission of satellites. Thermal loadings are usually simulated numerically and integrated in commercial softwares [1]. In this research, we have constructed an appropriate modeling for thermal loadings in the case of satellite's attitude being Earth-pointing. Thermal characteristics of nodes are analyzed based on these input thermal loadings. Our modeling is an extension of a previous paper on thermal radiation analysis for solar arrays of a small satellite in Low Earth Orbit [15].

\section{Thermal Balance Equations For Eight- Node Model of SMALl SATELlite}

\subsection{A satellite model and its orbit}

In Fig. 1 illustrates a small satellite moving in a Low Earth Orbit (LEO) at altitude of $680 \mathrm{~km}$. Satellite's orbit is Sun-synchronous and orbit plane is parallel with solar rays. The orbital period is 5902.25 seconds and the eclipse duration is 2121.2 seconds. For simulation, we suppose that the satellite always remains Earth-pointing attitude during motion. Simulation time starts at beginning of eclipse.

The small satellite is modeled as illustrated in Fig. 2. The satellite includes a body of size $L_{B} \times W_{B} \times H_{B}$ and a solar array of size $L_{A} \times W_{A}$. The distance from the solar array to satellite body is $\delta_{A B}$. Assume that the solar array is perpendicular to a side of satellite body. In fact, the solar array may be placed at different positions on the body depending on the configuration and mission of the satellite. Because the satellite thermal calculation is quite complex, the above model is a simplified one and will be a basis for the more complex satellite model. The body of the satellite is made from composite materials which have specific material and geometric parameters. Here, we suppose that material is homogeneous, which can be considered as a result after material homogenization. The absorptivity and emissivity coefficients of the body material are $\alpha_{B}$ and $\varepsilon_{B}$, respectively. The solar array is composed of many different materials. It includes two surfaces: front surface (surface 8) contains solar cells absorbed energy directly from Sun's rays; the absorptivity of the front surface is $\alpha_{F}$ whereas emissivity coefficient is denoted to be $\varepsilon_{F}$; and rear surface (surface 7 ) is coated by a material layer with absorptivity $\alpha_{R}$, and emissivity $\varepsilon_{R}$. The cover plates $1,2,3,4,5,6$ are numbered as shown in Fig.2. Plates 1 and 3 are opposite each other, in which plate 1 is closer to the solar array. Plates 2 and 4 are parallel each other and perpendicular to plates 1 and 3. Plates 5 and 6 are upper and base plates of the satellite, respectively.

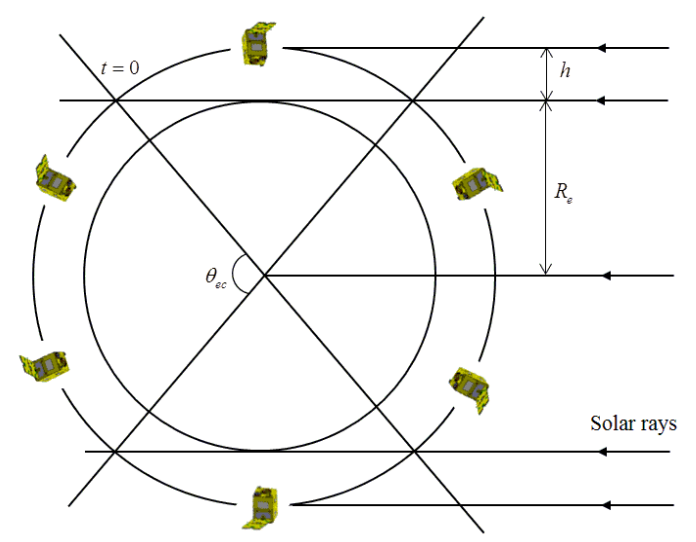

Figure 1. Earth-pointing attitude of the satellite

A local coordinate is associated with satellite and its origin is at the intersection of three planes 2, 3 and 5 (see Fig. 2). The axis $x$ is along the intersection between two planes 3 and 5, the axis $y$ is along the intersection between two planes 2 and 5 , the axis $z$ is along the intersection between two planes 2 and 3 . Numbers 1 to 8 indicate that the satellite structure is separated into eight-node with thermal characteristics assigned to each node.

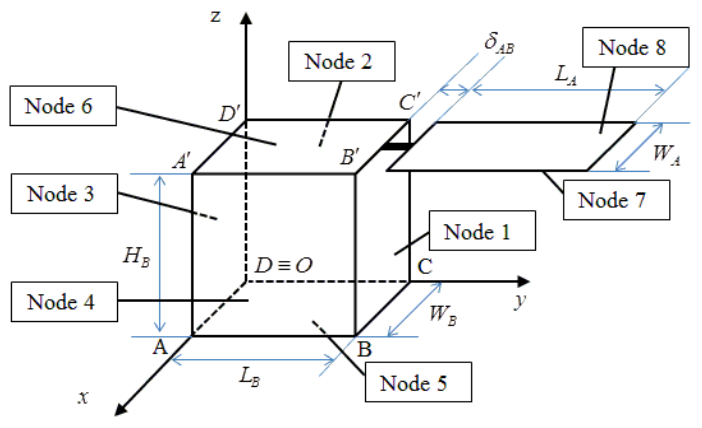

Figure 2. A model of a small satellite with size $L_{B} \times W_{B} \times H_{B}$ and nodes numbered from 1 to 8 


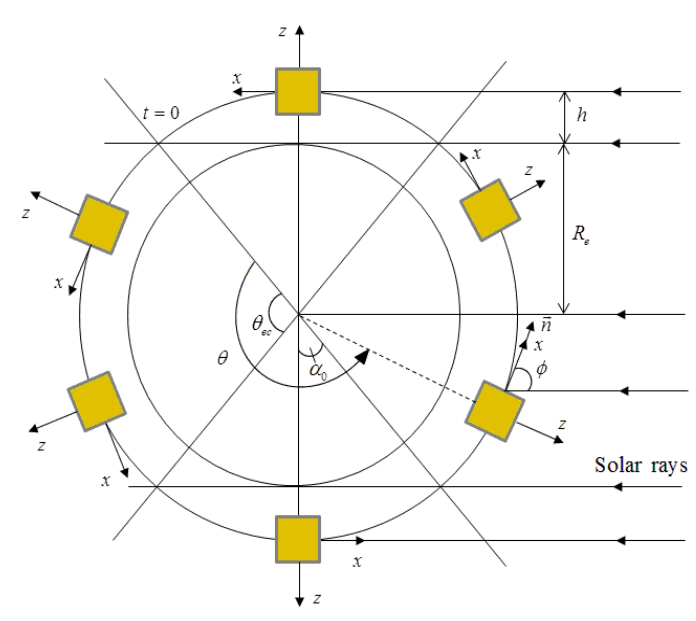

Figure 3. A orbital model for thermal calculations

In reality, each of plates numbered by indices from 1 to 6 has two sides: inside and outside surfaces. This way of numbering is because satellite plates have been assumed to be homogeneous material and therefore the material properties of the inside and outside are the same. It means that we can consider the inside and outside surfaces as a representative surface with an assigned index. However, the satellite array is modeled and numbered with two separated indices (7 and 8). This is because the physical property of the front surface that contains solar cells is very different from the rear surface.

\subsection{Thermal sources to satellite}

As mentioned above, there are three main heat sources from space environment consisting of solar irradiation, Earth's albedo and infrared radiation that affect to the thermal behavior of the satellite. From the Earth-pointing attitude of the satellite (see Fig. 1 or Fig. 3), we can obtain thermal fluxes acting to nodes. The order of nodes in thermal calculation is shown in Tab. 1. Parameter data for our calculations are given by Tab. 2. For detail, the values and physical characteristics of these parameters can be seen in $[1-3,10,12]$.

During motion, only six surfaces receive the thermal loadings from the space environment are $\mathrm{X}+, \mathrm{X}-, \mathrm{Z}+, \mathrm{Z}-$, front and rear surfaces; also for other two sides $\mathrm{Y}+$ and $\mathrm{Y}$-, the applied thermal loadings are considered to equal zero.
TABLE 1. THE ORder of Nodes IN THE THERMAL CALCUlation

\begin{tabular}{|c|c|c|c|c|c|c|c|}
\hline $\begin{array}{c}\text { Node } \\
\mathbf{1} \\
\left(B C C^{\prime} B^{\prime}\right)\end{array}$ & $\begin{array}{c}\text { Node } \\
\mathbf{2} \\
\left(C D D^{\prime} C^{\prime}\right)\end{array}$ & $\begin{array}{c}\text { Node } \\
\mathbf{3} \\
\left(A D D^{\prime} A^{\prime}\right)\end{array}$ & $\begin{array}{c}\text { Node } \\
\mathbf{4}\end{array}$ & $\begin{array}{c}\text { Node } \\
\mathbf{5}\end{array}$ & $\begin{array}{c}\text { Node } \\
\mathbf{6}\end{array}$ & $\begin{array}{c}\text { Node } \\
7\end{array}$ & $\begin{array}{c}\text { Node } \\
\mathbf{8}\end{array}$ \\
\hline $\mathrm{Y}+$ & $\mathrm{X}-$ & $\mathrm{Y}-$ & $\mathrm{X}+$ & $\mathrm{Z}-$ & $\mathrm{Z}+$ & $\begin{array}{c}\text { Rear } \\
\text { Surf. }\end{array}$ & $\begin{array}{c}\text { Front } \\
\text { Surf. }\end{array}$ \\
\hline
\end{tabular}

TABLE 2

MATERIAl PARAMETERS For THERMAL CALCULATION

\begin{tabular}{lc}
\hline System parameters & Values \\
Length of the body $L_{B}(\mathrm{~m})$ & 0.5 \\
Width of the body $L_{B}(\mathrm{~m})$ & 0.5 \\
Height of the body $H_{B}(\mathrm{~m})$ & 0.5 \\
Mass density of body plates $\rho_{B}\left(\mathrm{~kg} / \mathrm{m}^{3}\right)$ & 158.9 \\
Specific heat capacity of body plates $C_{p}^{B}(\mathrm{~J} / \mathrm{kgK})$ & 883.70 \\
Thickness of body plates $\delta_{B}(\mathrm{~m})$ & 0.02 \\
Material conductivity of the body $\lambda_{B}(\mathrm{~W} / \mathrm{mK})$ & 5.39 \\
Emissivity of the body material $\varepsilon_{B}$ & 0.82 \\
Absorbsivity of the body material $\alpha_{B}$ & 0.65 \\
Length of the solar array $L_{A}(\mathrm{~m})$ & 0.7 \\
Width of the solar array $W_{A}(\mathrm{~m})$ & 0.5 \\
Material conductivity of the solar array $\lambda_{A}$ & 2.79 \\
(W/mK) & 0.03 \\
Thickness of the solar array $\delta_{A}(\mathrm{~m})$ & 111.7 \\
Mass density of the solar array $\rho_{A}\left(\mathrm{~kg} / \mathrm{m}^{3}\right)$ & 844.40 \\
Specific heat capacity of the solar array $C_{p}^{A}$ & 6400.25 \\
(J/kgK) & 0.82 \\
Emissivity of front surface $\varepsilon_{F}$ & 0.69 \\
Absorbsivity of front surface $\alpha_{F}$ & 0.872 \\
Emissivity of rear surface $\varepsilon_{R}$ & 0.265 \\
Absorbsivity of rear surface $\alpha_{R}$ & 0.02 \\
The distance from array to body $\delta_{A B}(\mathrm{~m})$ & 1440 \\
Solar constant $G_{s}\left(\mathrm{Wm}{ }^{-2}\right)$ & 0.65 \\
Earth albedo coefficient $a$ & 259 \\
Earth black-body equivalent temperature $T_{e}(\mathrm{~K})$ & 680 \\
\hline
\end{tabular}

\subsubsection{Surface $X^{+}$}

For the surface $\mathrm{X}+$, only solar thermal flux $q_{s, X+}$ is present. It is determined as follows 


$$
q_{\mathrm{s}, \mathrm{X}+}=\left\{\begin{array}{lll}
0 & \text { if } & t \in\left[0, P_{e c}\right) \\
\alpha_{B} G_{s} \cos \left(\theta-\alpha_{0}-\theta_{e c}\right) & \text { if } & t \in\left[P_{e c}, \frac{P_{e c}+P_{o r b}}{2}\right) \\
0 & \text { if } & t \in\left[\frac{P_{e c}+P_{o r b}}{2}, P_{o r b}\right]
\end{array}\right.
$$

where $G_{s}$ is the mean solar radiation, $P_{e c}$ and $P_{o r b}$ are the eclipse and orbital periods, respectively. The basis for formulating this expression can view in [1-3]. In (1), we have denoted

$$
\begin{array}{r}
\theta=v t, v=\frac{2 \pi}{P_{o r b}}, \alpha_{0}=\arccos \left(\frac{R_{e}}{R_{e}+h}\right), \\
\theta_{e c}=\pi-2 \alpha_{0}
\end{array}
$$

The solar flux on the surface $X+$ is a periodic function of time $\mathrm{t}$ as presented in Fig. 4 in an orbital period.

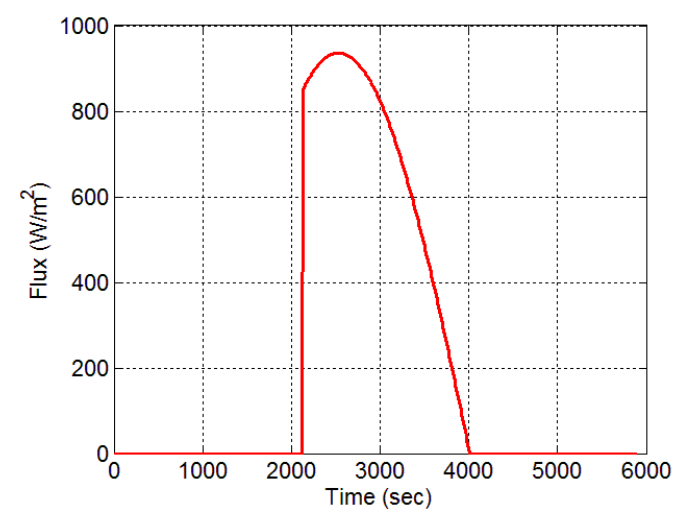

Figure 4. Solar flux on surface $\mathrm{X}+$ with parameters given in Tab. 2

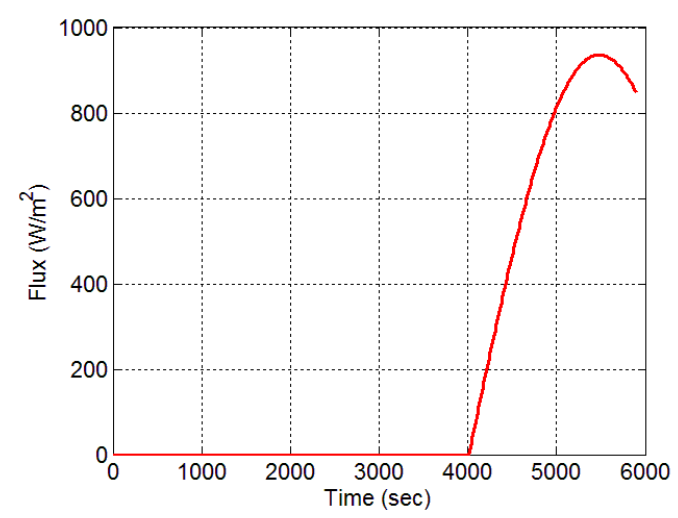

Figure 5. Solar flux on surface $\mathrm{X}$ - with parameters given in Tab. 2

\subsubsection{Surface $X$ -}

For the surface X-, it absorbs only solar thermal flux $q_{s, X-}$ and is calculated as follows

$$
q_{\mathrm{s}, \mathrm{X}-}= \begin{cases}0 & \text { if } t \in\left[0, \frac{P_{e c}+P_{o r b}}{2}\right) \\ \alpha_{B} G_{s} \cos \left(2 \pi-\alpha_{0}-\theta\right) & \text { if } t \in\left[\frac{P_{e c}+P_{o r b}}{2}, \frac{1}{2}\left(2-\frac{\alpha_{0}}{\pi}\right) P_{o r b}\right) \\ \alpha_{B} G_{s} \cos \left(\theta-\left(\theta_{e c}+\alpha_{0}+\pi\right)\right) & \text { if } t \in\left[\frac{1}{2}\left(2-\frac{\alpha_{0}}{\pi}\right) P_{o r b}, P_{o r b}\right]\end{cases}
$$

The graph of $q_{s, X-}$ is plotted in Fig. 5. It is also a periodic function of time $t$.

Similarly, the expressions for thermal loadings acting on the surface Z+ and Z- can be easily obtained. Here we present two other loadings for the front and rear surfaces of solar array.

\subsubsection{Front surface}

For the front surface, only solar thermal flux $q_{s, F S}$ is present. It is determined as follows

$$
q_{s, F S}= \begin{cases}0 & \text { if } t \in\left[0, \frac{1}{2}\left(1-\frac{\alpha_{0}}{\pi}\right) P_{o r b}\right) \\ \alpha_{F} G_{s} \cos \left(\theta-\pi-\frac{\theta_{e c}}{2}\right) & \text { if } t \in\left[\frac{1}{2}\left(1-\frac{\alpha_{0}}{\pi}\right) P_{o r b}, \frac{1}{2}\left(2-\frac{\alpha_{0}}{\pi}\right) P_{o r b}\right] \\ 0 & \text { if } t \in\left(\frac{1}{2}\left(2-\frac{\alpha_{0}}{\pi}\right) P_{o r b}, P_{o r b}\right]\end{cases}
$$

The graph of $q_{s, F S}$ is illustrated in Fig. 6 .

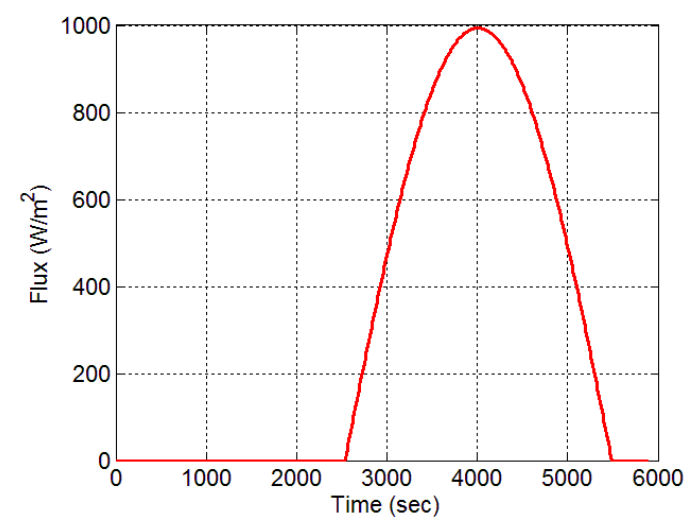

Figure 6. Solar flux on the front surface

\subsubsection{Rear surface}

There are three thermal fluxes that affect to the rear surface: solar, albedo and infrared fluxes. The mathematical representation for them can be estimated as follows 


$$
q_{\mathrm{s}, \mathrm{RS}}= \begin{cases}0 & \text { if } \quad t \in\left[0, P_{e c}\right) \\ \alpha_{R} G_{s} \cos \left(\theta-\frac{\theta_{e c}}{2}\right) & \text { if } \quad t \in\left[P_{e c}, \frac{1}{2}\left(1-\frac{\alpha_{0}}{\pi}\right) P_{o r b}\right) \\ 0 & \text { if } \quad t \in\left[\frac{1}{2}\left(1-\frac{\alpha_{0}}{\pi}\right) P_{o r b}, \frac{1}{2}\left(2-\frac{\alpha_{0}}{\pi}\right) P_{o r b}\right) \\ \alpha_{R} G_{s} \cos \left(2 \pi-\theta+\frac{\theta_{e c}}{2}\right) & \text { if } \quad t \in\left[\frac{1}{2}\left(2-\frac{\alpha_{0}}{\pi}\right) P_{o r b}, P_{o r b}\right]\end{cases}
$$$$
q_{a, R S}= \begin{cases}0 & \text { if } t \in\left[0, \frac{1}{2}\left(1-\frac{\alpha_{0}}{\pi}\right) P_{o r b}\right) \\ \alpha_{R} G_{s} a F_{R S, e} \cos \left(\pi-\theta+\frac{\theta_{c c}}{2}\right) & \text { if } t \in\left[\frac{1}{2}\left(1-\frac{\alpha_{0}}{\pi}\right) P_{o r b}, \frac{1}{2}\left(2-\frac{\alpha_{0}}{\pi}\right) P_{o r b}\right] \\ 0 & \text { if } t \in\left(\frac{1}{2}\left(2-\frac{\alpha_{0}}{\pi}\right) P_{o r b}, P_{o r b}\right]\end{cases}
$$

$$
q_{I R, \mathrm{RS}}=\varepsilon_{R} F_{\mathrm{RS}, e} \sigma T_{e}^{4}
$$

Here, $a$ is the albedo factor of the Earth; $T_{e}$ is the Earth's black-body equivalent temperature. The graphs of $q_{s, \mathrm{RS}}, q_{a, \mathrm{RS}}$ and $q_{I R, \mathrm{RS}}$ are delineated in Fig. 7. In calculations of infrared loadings, we pay attention to view factor between the satellite and the Earth. There are two surfaces (surface Z- and rear surface) which have view factors differ from zero, i.e. $F_{Z-, \mathrm{e}} \neq 0$ and $F_{R S, e} \neq 0$. Other surface's view factor are considered equal zero. The view factor depends on the altitude of the satellite orbit. Because the surface areas of the satellite are rather small, they can be considered as differential surfaces. So that, we can compute view factor from a differential surface to the Earth's sphere. On calculating view factor, readers can be seen in detail in the book by Howell et al. [12].

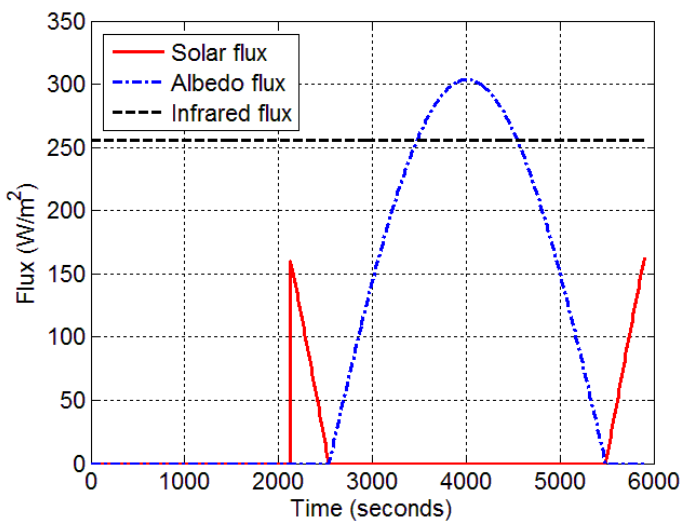

Figure 7. Thermal fluxes on the rear surface
TABLE 3

\begin{tabular}{ccc} 
VALUES OF $C_{i}$ AND & $Q_{d i s, i}$ FOR THERMAL CALCULATION \\
\hline Node & $C_{i}, \mathrm{~J} / \mathrm{K}$ & $Q_{d i s, i}, \mathrm{~W}$ \\
\hline $\mathbf{1}$ & 702.1 & 10 \\
$\mathbf{2}$ & 702.1 & 10 \\
$\mathbf{3}$ & 702.1 & 10 \\
$\mathbf{4}$ & 702.1 & 10 \\
$\mathbf{5}$ & 702.1 & 10 \\
$\mathbf{6}$ & 702.1 & 10 \\
$\mathbf{7}$ & 1131.8 & 15 \\
$\mathbf{8}$ & 1131.8 & 15 \\
\hline
\end{tabular}

\subsection{Thermal balance equations}

As has been stated in the previous section, our satellite can be thermally modeled with eight nodes. Let $C_{i}$ be the thermal capacities of the nodes, and $T_{i}$ be their temperatures $(i=1, \ldots, 8)$. The geometric model corresponding to this thermal mathematical model is shown in Fig.2. The nodes are thermally coupled by both conduction and radiation, and also radiation interaction to space environment. Let $K_{i j}$ be the conductive coupling coefficient and $R_{i j}$ the radiative coupling coefficient. The energy balance equations for the nodes are

$C_{i} \dot{T}_{i}=\sum_{j=1}^{n} K_{i j}\left(T_{j}-T_{i}\right)+\sum_{j=1}^{n} R_{i j}\left(T_{j}^{4}-T_{i}^{4}\right)+R_{i \infty}\left(T_{\infty}^{4}-T_{i}^{4}\right)+Q_{e x t, i}+Q_{d i s, i}$

where $Q_{\text {ext,i }}$ represents the external thermal load on the node $\mathrm{i}$, and $Q_{d i s, i}$ represents the heat dissipation of the node $\mathrm{i}$.

Taking into account the input parameter information in Tab. 2, and nodes are assumed to be undergone a constant heat dissipation level (in W), it is possible to calculate the capacities $C_{i}$, $\mathrm{i}=1, \ldots, 8$, with results given in Tab. 3 . We obtain the following conduction (in $\mathrm{W} / \mathrm{K}$ ) and radiation (in $\left.\mathrm{W} / \mathrm{K}^{4}\right)$ matrices:

$$
\begin{gathered}
\mathbf{K}=\left[K_{i j}\right]_{8 \times 8}= \\
\left(\begin{array}{ccccccccc}
0 & 0.1078 & 0 & 0.1078 & 0.1078 & 0.1078 & 0 & 0 \\
0.1078 & 0 & 0.1078 & 0 & 0.1078 & 0.1078 & 0 & 0 \\
0 & 0.1078 & 0 & 0.1078 & 0.1078 & 0.1078 & 0 & 0 \\
0.1078 & 0 & 0.1078 & 0 & 0.1078 & 0.1078 & 0 & 0 \\
0.1078 & 0.1078 & 0.1078 & 0.1078 & 0 & 0 & 0 & 0 \\
0.1078 & 0.1078 & 0.1078 & 0.1078 & 0 & 0 & 0 & 0 \\
0 & 0 & 0 & 0 & 0 & 0 & 0 & 32.55 \\
0 & 0 & 0 & 0 & 0 & 0 & 32.55 & 0
\end{array}\right)
\end{gathered}
$$




$$
\begin{aligned}
& \mathbf{R}=\left[R_{i j}\right]_{8 \times 8}=10^{-8} \times \\
& \left(\begin{array}{cccccccccc}
0 & 0.1971 & 0.1968 & 0.1971 & 0.1971 & 0.1971 & 0.1531 & 0 \\
0.1971 & 0 & 0.1971 & 0.1968 & 0.1971 & 0.1971 & 0 & 0 \\
0.1968 & 0.1971 & 0 & 0.1971 & 0.1971 & 0.1971 & 0 & 0 \\
0.1971 & 0.1968 & 0.1971 & 0 & 0.1971 & 0.1971 & 0 & 0 \\
0.1971 & 0.1971 & 0.1971 & 0.1971 & 0 & 0.1968 & 0 & 0 \\
0.1971 & 0.1971 & 0.1971 & 0.1971 & 0.1968 & 0 & 0 & 0 \\
0.1531 & 0 & 0 & 0 & 0 & 0 & -0.1531 & 0 \\
0 & 0 & 0 & 0 & 0 & 0 & 0 & 0
\end{array}\right)
\end{aligned}
$$

$$
\mathbf{R}_{\infty}=\left[R_{i \infty}\right]_{8 \times 1}=10^{-9} \times
$$

$\left(\begin{array}{llllllll}0.1162 & 0.1162 & 0.1162 & 0.1162 & 0.1162 & 0.1162 & 0.1730 & 0.1627\end{array}\right)^{T}$

The system (8) can be rewritten in the following matrix form for eight-node model

$$
\overline{\mathbf{C}} \mathbf{T}=\overline{\mathbf{K}} \mathbf{T}+\overline{\mathbf{R}} \mathbf{T}^{4}-\overline{\mathbf{R}}_{\infty} \mathbf{T}^{4}+\overline{\mathbf{R}}_{\infty} \mathbf{T}_{\infty}^{4}+\overline{\mathbf{Q}}_{\mathrm{ext}}+\overline{\mathbf{Q}}_{\mathrm{d}}
$$

where $\quad \mathbf{T}=\left[\begin{array}{llll}T_{1} & T_{2} & \ldots & T_{8}\end{array}\right]^{T}$ is a generalized vector; $\overline{\mathbf{C}}$ is the extended thermal capacity and $\overline{\mathbf{K}}$, $\overline{\mathbf{R}}, \overline{\mathbf{R}}_{\infty}$ are the extended conduction and radiation matrices obtained from the original matrices $\mathbf{K}$, $\mathbf{R}, \mathbf{R}_{\infty}$ by rearranging elements $T_{i}, T_{j}$ of Eq. (8) to get the form (12). $\quad \overline{\mathbf{Q}}_{\text {ext }}(t)$ is a vector of external thermal loadings; $\overline{\mathbf{Q}}_{\mathbf{d}}$ is a vector of the dissipation of nodes; $\mathbf{T}^{4}=\left[\begin{array}{llll}T_{1}^{4} & T_{2}^{4} & \ldots & T_{8}^{4}\end{array}\right]^{T}$ denotes a vector of radiation terms.

Assume that the thermal capacity matrix is not singular (i.e. $\operatorname{det}(\overline{\mathbf{C}}) \neq 0$ ). Pre-multiplying both side of Eq. (12) by $\overline{\mathbf{C}}^{-1}$, we obtain

$$
\dot{\mathbf{T}}=\overline{\mathbf{C}}^{-1}\left[\overline{\mathbf{K}} \mathbf{T}+\overline{\mathbf{R}} \mathbf{T}^{4}-\overline{\mathbf{R}}_{\infty} \mathbf{T}^{4}+\overline{\mathbf{R}}_{\infty} \mathbf{T}_{\infty}^{4}+\overline{\mathbf{Q}}_{\text {ext }}(t)+\overline{\mathbf{Q}}_{\mathbf{d}}\right]
$$

In the next section, we will solve Eq. (13) using Runge-Kutta algorithm to get numerical solutions of thermal responses of nodes.

\section{RUNGE-KUTTA METHOD}

The Runge-Kutta (RK) method is one of the most well-known methods for finding approximate solutions of ordinary differential equations in problems of numerical analysis. It was developed around 1900 by two German mathematicians C. Runge and M. W. Kutta $[13,14]$. In this section, we use fourth-order RK method to find temperature responses of nodes of the small satellite under consideration. Our attention is to solve Eq. (13) to explore thermal characteristics of nodes when thermal nodes are subjected to radiation loadings from space environment.

We consider a generalized ordinary differential equations system in the following form

$$
\dot{\mathbf{T}}=\mathbf{F}(t, \mathbf{T})
$$

where $\mathbf{T}=\left[\begin{array}{llll}T_{1} & T_{2} & \ldots & T_{n}\end{array}\right]^{T}$ is a generalized vector, $\mathbf{F}=\left[\begin{array}{lllll}F_{1} & F_{2} & \ldots & F_{n}\end{array}\right]^{T}$ is a nonlinear n-vector function which contains linear and nonlinear terms

$$
F_{i}=F_{i}\left(t, T_{1}, T_{2}, \ldots, T_{n}\right),(i=\overline{1, n}),
$$

and $T_{1}, T_{2}, \ldots, T_{n}$ are functions of time $t \in\left[t_{0}, \mathrm{t}_{F}\right]$.

To calculate numerical solutions, we divide the time interval $\left[t_{0}, \mathrm{t}_{F}\right]$ into $n$ equal segments by $(n+1)$ points $t_{i}: t_{i}=t_{0}+i h ; t_{n}=t_{F} ; \quad h=\frac{t_{F}-t_{0}}{n}$. The set of points $t_{i}$ creates a "differential net", each point is called a grid node, $h$ is called the mesh step. We can estimate the approximate value of $T_{i+1}=T\left(t_{i+1}\right)$ from $T_{i}=T\left(t_{i}\right)$ as follows

$$
T_{i+1}=T_{i}+\frac{h}{6}\left(\mathrm{k}_{1}+2 \mathrm{k}_{2}+2 \mathrm{k}_{3}+\mathrm{k}_{4}\right),
$$

where

$$
\begin{aligned}
\mathrm{k}_{1} & =\mathbf{F}\left(t_{i}, T_{i}\right) ; \\
\mathrm{k}_{2} & =\mathbf{F}\left(t_{i}+\frac{h}{2}, T_{i}+\frac{h}{2} \mathrm{k}_{1}\right) ; \\
\mathrm{k}_{3} & =\mathbf{F}\left(t_{i}+\frac{h}{2}, T_{i}+\frac{h}{2} \mathrm{k}_{2}\right) ; \\
\mathrm{k}_{4} & =\mathbf{F}\left(t_{i}+h, T_{i}+h \mathrm{k}_{3}\right),
\end{aligned}
$$

The Runge-Kutta method will be applied to system (13) where the function $\mathbf{F}$ is given by

$$
\mathbf{F}(t, \mathbf{T})=\overline{\mathbf{C}}^{-1}\left[\overline{\mathbf{K}} \mathbf{T}+\overline{\mathbf{R}} \mathbf{T}^{4}-\overline{\mathbf{R}}_{\infty} \mathbf{T}^{4}+\overline{\mathbf{R}}_{\infty} \mathbf{T}_{\infty}^{4}+\overline{\mathbf{Q}}_{\text {ext }}(t)+\overline{\mathbf{Q}}_{\mathbf{d}}\right]
$$

Numerical results for Eq. (13) will be presented in next section. 


\section{NuMERICAL RESULTS AND DISCUSSION}

Temperature evolutions in time of eight nodes of satellite are shown in Fig. 8. It is observed that, when the satellite is in the illuminated region of orbit, temperatures of solar array are larger than that of other nodes. The maximum temperature is predicted to be $82.4722{ }^{\circ} \mathrm{C}$ for node 8 (the front surface) and $80.2318{ }^{\circ} \mathrm{C}$ for node 7 (the rear surface) of solar array (see Tab. 4). There is a slight difference between temperatures of nodes 7 and 8 because the conduction thickness between these two nodes is very small in comparison with the length of solar array. In the eclipse region of orbit, the minimum temperatures of nodes 1,2, 3, 4 and 6 are nearly the same, about $-60{ }^{\circ} \mathrm{C}$. In this region, the received thermal of the nodes 1,2, 3, 4 and 6 from environment is very low. The change of temperatures between nodes is due to the thermal interactions via the conduction and radiation. For three nodes 5, 7 and 8 , the minimum temperatures are higher than others. By taking the estimated mean of maximum and minimum temperatures, we can see that the estimated mean of node 5 is highest because it always remains a thermal flux acted by Earth's infrared radiation (see Tab. 4).

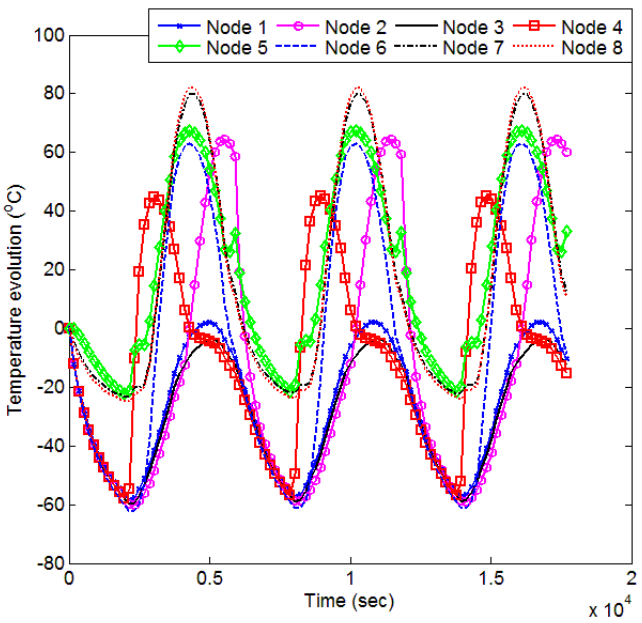

Figure 8. Temperature evolutions in time of eight nodes of satellite

TABLE 4

MINIMUM AND MAXIMUM TEMPERATURES OF NODES FOR THE PARAMETERS' VALUES GIVEN IN TABLE 2

\begin{tabular}{cccc}
\hline Node & $\operatorname{Min}\left({ }^{\circ} \mathrm{C}\right)$ & $\operatorname{Max}\left({ }^{\circ} \mathrm{C}\right)$ & $\begin{array}{c}\text { Estimated } \\
\text { mean }\left({ }^{\circ} \mathrm{C}\right)\end{array}$ \\
\hline $\mathbf{1}$ & -57.1998 & 2.2558 & -27.4720 \\
$\mathbf{2}$ & -59.0681 & 64.4913 & 2.7116 \\
$\mathbf{3}$ & -59.0294 & -3.5636 & -31.2965 \\
$\mathbf{4}$ & -58.3320 & 45.2248 & -6.5536 \\
$\mathbf{5}$ & -22.4952 & 67.4134 & 22.4591 \\
$\mathbf{6}$ & -61.5191 & 62.9609 & 0.7209 \\
$\mathbf{7}$ & -22.6112 & 80.2318 & 11.5160 \\
$\mathbf{8}$ & -24.1244 & 82.4722 & 12.6362 \\
\hline
\end{tabular}

It is observed that, the predicted maximum and minimum temperatures of satellite's body and solar array belong to the range of temperature requirements given in Tab 5 .

TABLE 5. THERMAL REQUIREMENTS [3]

\begin{tabular}{ccc}
\hline Temperature & Min $\left({ }^{\circ} \mathbf{C}\right)$ & Max $\left({ }^{\circ} \mathbf{C}\right)$ \\
\hline Solar arrays & -100 & +120 \\
Inactive structure & -100 & +100 \\
\hline
\end{tabular}

Fig. 9 depicts the change of temperature evolutions of node 8 with various values of absorbtivity $\alpha_{F}$. The value of $\alpha_{F}$ shows the absorbed part of incoming radiation to the total incoming radiation of the front surface. In the case of large value of $\alpha_{F}$, maximum temperature of node 8 grows rapidly. This shows that a strong effect of the absorbitivity on the temperature of node 8 when the satellite is in the illuminated region of orbit. In Fig. 10, the difference between the maximum temperatures of front surface with various values of $\alpha_{F}$ when compared to the case $\alpha_{F}=0.92$ is computed. This difference value is largest if absorbtivity $\alpha_{F}$ takes small value, for example $\alpha_{F}=0.1$. The value of the temperature difference is reduced if the solar absorbtivity $\alpha_{F}$ increases.

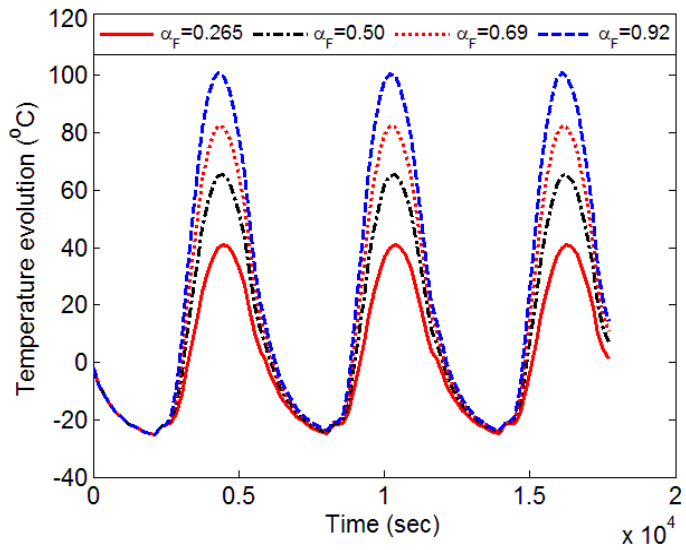

Figure. 9. Temperature evolutions of front surface (node 8) with various absorbtivity $\alpha_{F}$ 


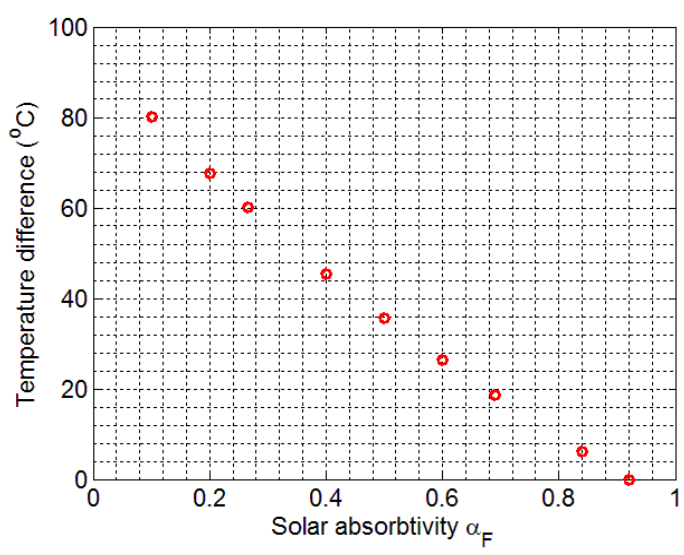

Figure 10. The errors between the maximum temperatures of front surface (node 8) with various values of $\alpha_{F}$ when compared to the case $\alpha_{F}=0.92$

Fig. 11 presents the temperature evolution of node 8 with different values of emissitivity coefficient $\varepsilon_{F}$. The emissitivity is taken from 0.5 to 0.82 . Three values are selected, $\varepsilon_{F}=0.5$, $\varepsilon_{F}=0.7$ and $\varepsilon_{F}=0.82$. It is seen that as the emissitivity is increasing, the temperature of node 8 decreases.

The thermal interaction between two nodes 7 and 8 is shown in Fig. 12. The dependence of node 8's temperature on the node 7's temperature is nearly linear because the difference of temperatures between them is quite small.

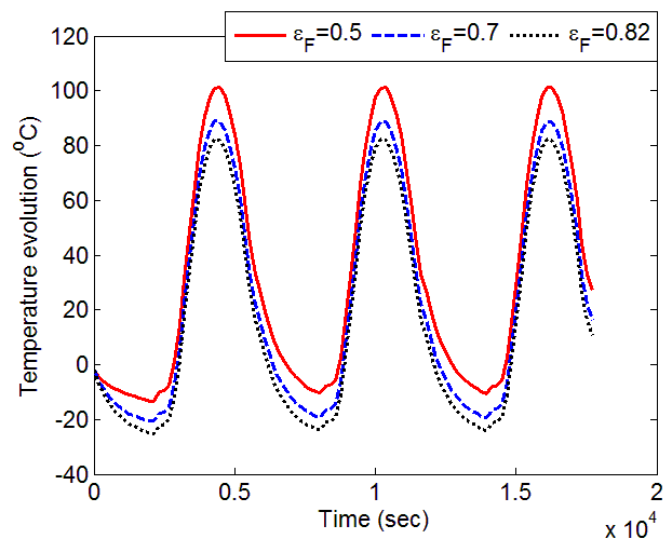

Figure 11. Temperature evolutions of front surface (node 8) with various emissitivity $\varepsilon_{\mathrm{F}}$

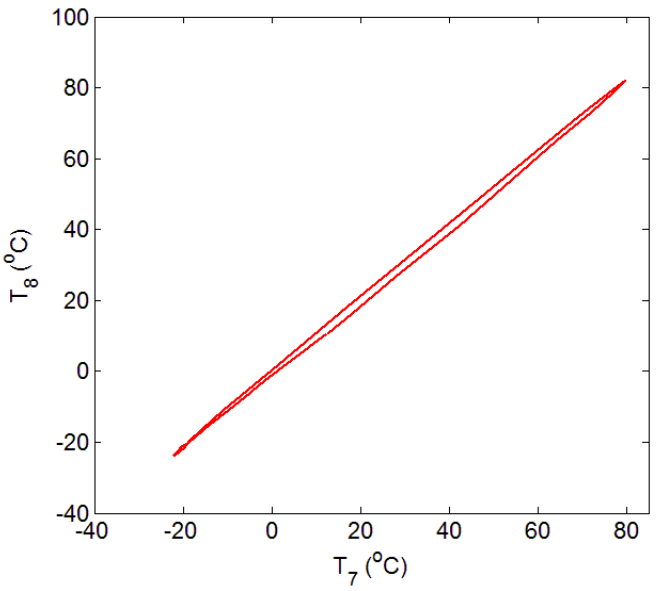

Figure 12. Temperature of front surface $T_{8}$ versus temperature of rear surface $\mathrm{T}_{7}$

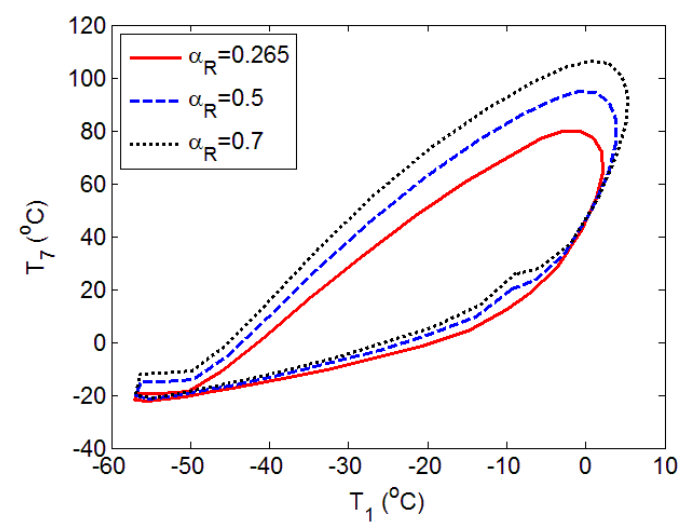

Figure 13. Temperature of rear surface (node 7) $\mathrm{T}_{7}$ versus temperature of surface $\mathrm{Y}+$ (node 1$) \mathrm{T}_{1}$, with various absorbtivity $\alpha_{R}$

In Fig. 13, we portray the thermal interaction between nodes 1 (of satellite's body) and 7 (of solar array) with various values of node 7's absorbtivity $\alpha_{R}$. For each value of $\alpha_{R}$, in the steady-state, the temperatures of node 1 and 7 can reach a limit cycle. The shape of the limit cycle in this case is not a circle or ellipse because the obtained thermal responses of node 1 and 7 are not harmonic but almost periodic.

\section{CONCLUSION}

The results of analysis for thermal characteristics of a satellite structure have turned out to be extremely useful in the framework of a satellite mission. In this research, a simplified model of satellite are carried out using the method of lumped parameters for nodes. The numerical results of nodal temperatures are implemented with the use of the Runge-Kutta method. Several main 
results are obtained and can be summated as follows:

- A modeling of thermal loadings from space environment is established in the framework of Low Earth Orbit.

- A simplified model with eight nodes representing for the body plates and solar array is constructed based on the geometrical dimensions and material properties of satellite.

- The thermal balance equations for nodes are derived from the characteristics of conduction and radiation interactions between nodes and external thermal loadings.

- The temperature evolutions in time of nodes are obtained using the Runge-Kutta algorithm with representations of the extended thermal capacity, conduction and radiation matrices obtained from the rearrangement of thermal nodes in thermal balance equations.

- The effects of material properties such as absorbtivity and emissivity on the thermal responses of nodes are explored.

- The maximum and minimum temperature information of nodes shows that the predicted temperatures of the satellite obtained from numeral analyses are within the allowable temperature limit range of satellite.

\section{REFERENCES}

[1] D. G. Gilmor, "Spacecraft Thermal Control Handbook", The Aerospace Corporation, 2002.

[2] P. Fortescue, G. Swinerd, J. Stark, "Spacecraft System Engineering", John Wiley \& Son Ltd., 2003.

[3] J.Meseguer, I. Pérez-Grande and A. Sanz-Andrés, "Spacecraft thermal control", Woodhead Publishing, 2012

[4] K. Oshima, Y. Oshima, "Analytical approach to the thermal design of spacecraft", Institute of Space and Aeronautical Science of Tokyo, Report No. 419, 1968.

[5] C. Arduini, G. Laneve, S. Folco, "Linearized techniques for solving the inverse problem in the satellite thermal control", Acta Astronautica, vol. 43, pp. 473-4789, 1998.

[6] J. Gaite, A. S. Andres, I. P. Grande, "Nonlinear analysis of a simple model of temperature evolution in a satellite", Nonlinear Dynamics, vol. 58, pp. 405-415, 2009.

[7] I. P. Grande, A. S. Andres, C. Guerra, G. Alnonso, "Analytical study of the thermal behaviour and stability of a small satellite", Applied Thermal Engineering, vol. 29, pp. 2567-2573, 2009.

[8] J. Gaite, A. S. Andres, I. P. Grande, "Nonlinear analysis of a simple model of temperature evolution in a satellite", Nonlinear Dynamics, vol. 58, pp. 405-415, 2009.

[9] J. Gaite, G. Fernández-Rico, "Linear approach to the orbiting spacecraft thermal problem", Journal of Thermophysics and Heat Transfer, vol. 26, pp. 511-522, 2012.

[10] N. D. Anh, N. N. Hieu, P. N. Chung, N. T. Anh, "Thermal radiation analysis for small satellites with single-node model using techniques of equivalent linearization", Applied Thermal Engineering, vol. 94, pp. 607-614, 2016.

[11] J. Gaite, "Nonlinear analysis of spacecraft thermal models", Nonlinear Dynamics, vol. 65, pp. 283-300, 2011.

[12] J. R.Howell, R. Siegel, M P. Menguc, "Thermal Radiation Heat Transfer", Taylor \& Francis Group, 2010.

[13] J. C. Butcher, "Numerical Methods for Ordinary Differential Equations", New York: John Wiley \& Sons, 2008, ISBN 978-0-470-72335-7.

[14] A. Iserles, "A First Course in the Numerical Analysis of Differential Equations", Cambridge University Press, 1996, ISBN 978-0-521-55655-2.

[15] P. N. Chung, N. N. Hieu, N. D. Anh, "Thermal radiation analysis for solar arrays of a small satellite in Low Earth Orbit", The 4th International Conference on Engineering Mechanics and Automation (ICEMA 4) Hanoi, August $25 \div 26,2016$, pp. $146-153$.

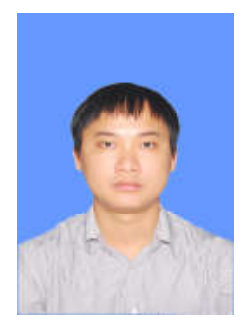

Pham Ngoc Chung was born in Ninh Binh province in Viet Nam. He graduated from Faculty of Mathematics, Mechanics and Informatics in VNU University of Science. He got the B.S. and M.S degree in Mechanics in 2010 and 2014, respectively. His current job is a lecturer in University of Mining and Geology. His research interest consists algebraic systems, numerical simulation, nonlinear dynamical systems, thermal analysis and control for satellites. $\mathrm{He}$ has published about ten scientific papers in National Conferences and International Journals.

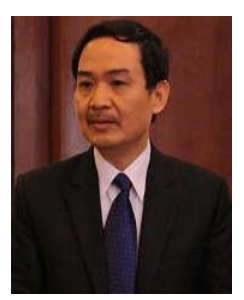

Nguyen Dong Anh was born in Hanoi, Vietnam, in 1954. He received the D.Sc degree in Vibration in 1986. He was promoted to Professor in 1996. Currently, he is working at the Institute of Mechanics, Vietnam Academy of Science and Technology as Chairman of the Board of Scientists. His research interest includes vibration, nonlinear random oscillation, oscillation control, nonlinear dynamical systems. He has published more than 100 scientific articles in National and International Journals. He was also the author of two monograph books. $\mathrm{He}$ successfully taught and educated many masters and doctors. 


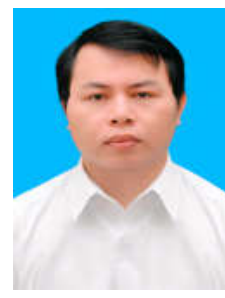

Nguyen Nhu Hieu was born in Bac Ninh province, Vietnam. He received the B.S. and M.S. degrees in Mechanics of Solids from the Hanoi National University in 2008 and 2011, respectively. At present, he works at the Institute of Mechanics, Vietnam Academy of Science and Technology. His current areas of interest include applied mathematics and nonlinear dynamical systems. He has published more than twenty scientific papers in National Conferences and International Journals. 


\title{
Phân tích ứng xử nhiệt phi tuyến của vệ tinh nhỏ trên quỹ đạo thấp sử dụng mô hình nhiều nút
}

\author{
Phạm Ngọc Chung, Nguyễn Đông Anh, Nguyễn Như Hiếu
}

Tóm tắt - Trong bài báo này, đáp ứng nhiệt phi tuyến của một vệ tinh nhỏ trên quỹ đạo thấp của Trái đất được phân tích dựa trên mô hình nhiệt nhiều nút. Các thành phẩn kết cấu chính của một vệ tinh dạng hình hộp gồm có thân với sáu mặt hình chữ nhật và một cánh nối với thân. Các thành phần thân và cánh có thể được mô hình hóa trên cơ sở phương pháp nhiệt phân bổ, nghĩa là mỗi mặt của thân và cánh được đặc trưng bởi một nút nhiệt. Để ước lượng nhiệt độ cho các thành phần này, chúng ta có thể sử dụng mô hình nhiệt tám nút: sáu nút cho các mặt của thân và hai nút cho mặt trước và mặt sau của cánh. Các nút hấp thụ ba nguồn nhiệt chủ yếu từ môi trường không gian bao gồm bức xạ mặt trời, bức xạ albedo và bức xạ hồng ngoại Trái đất. Hệ phương trình cân bằng nhiệt xác lập cho các nút là hệ phương trình vi phân phi tuyến và được giải bằng một phương pháp số. Với mục đích mô phỏng, giả sử rằng vệ tinh luôn duy trì ở tư thế "Earth-pointing" trong suốt thời gian nó chuyển động trên quỹ đạo.Tiển triển nhiệt độ theo thời gian của các nút sẽ được nghiên cứu một cách chi tiết. Kết quả thu được chỉ ra giá trị nhiệt độ dụ̣ đoán của các nút nằm trong giới hạn nhiệt cho phép của vệ tinh.

Tù khóa - vệ tinh nhỏ, Earth-pointing, đáp ứng nhiệt, giới hạn nhiệt. 